DOSSIÊ

\title{
Sobre o conceito de trabalho: uma leitura nos Grundrisse, de Marx
}

On the concept of work: reading Marx's crundrisse

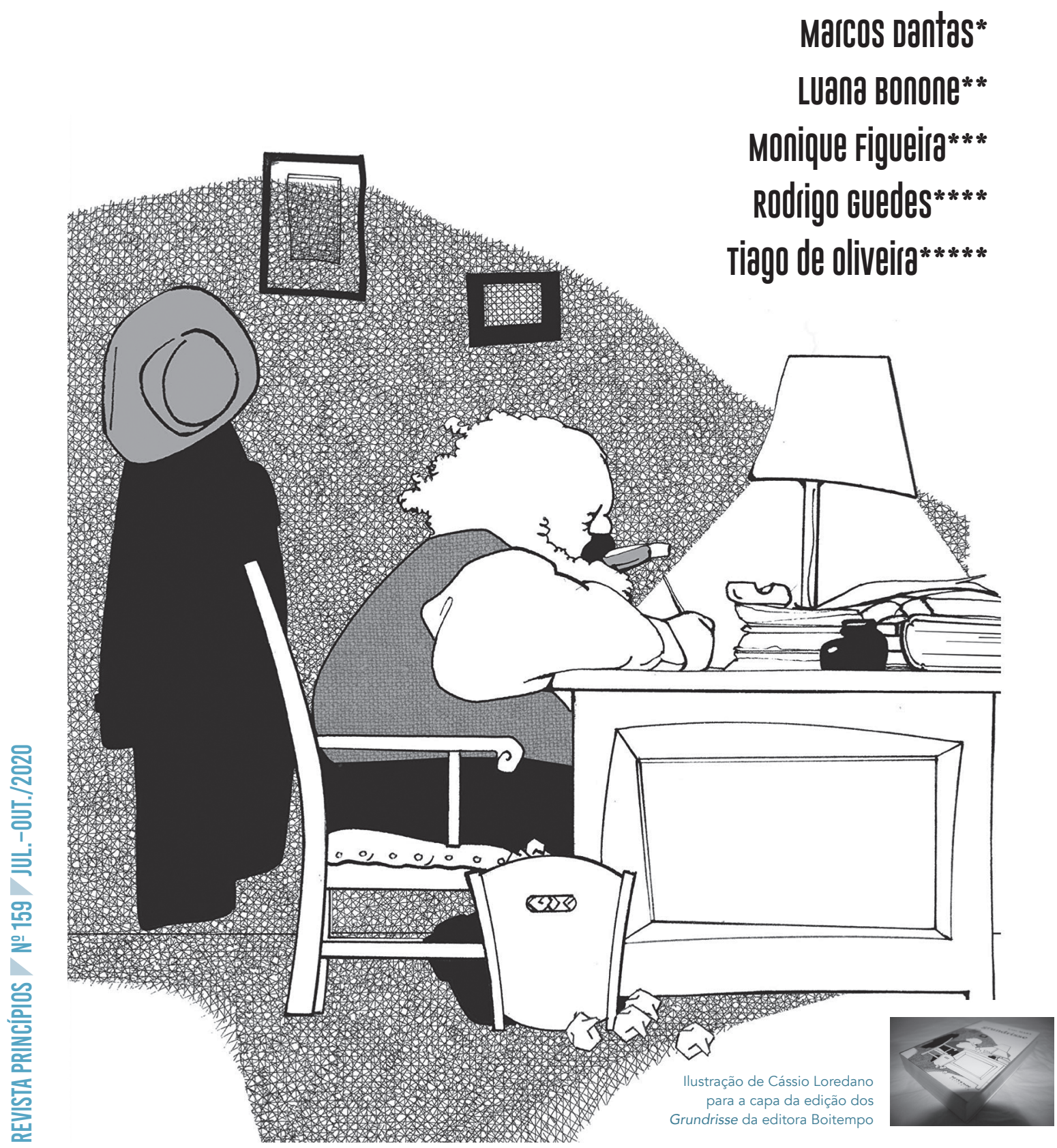




\section{RESUMO}

Marx antecipava nos Grundrisse a transformação da ciência e tecnologia em forças produtivas diretas no capitalismo. Esse processo levaria à predominância do trabalho intelectual sobre o manual, substituído pelas máquinas. O capital, então, haveria de ser superado por alguma formação apoiada no intelecto geral da sociedade. Por isso, debate-se se a lei do valor, baseada no tempo de trabalho, teria sido superada ou se seria necessário redefinir a categoria trabalho. Este artigo pretende apontar lacunas nesse debate, articulando a concepção dialética da história em Marx com os conceitos científicos da teoria da informação. Ao relacionar trabalho à informação como neguentropia, entendemos o capital como um sistema biossocial sempre em expansão e dependente do conhecimento detido pelo trabalhador. Assim, concluímos que o capital evoluiu a ponto de se apropriar do intelecto geral. Como o capital, na sua evolução, reduziu ao mínimo o tempo de trabalho fabril imediato, subalterno ao trabalho científico, para seguir acumulando precisou desenvolver um sistema rentista apoiado na propriedade intelectual e na financeirização. A lei do valor segue comandando as relações de trabalho, agora sob novas formas de apropriação de trabalho gratuito, precarização e fragmentação espaço-temporal, com superexploração do trabalho de baixo valor informacional nas periferias do sistema.

Palavras-chave: Trabalho; General intellect; Marxismo; Renda informacional; Trabalho semiótico.

\section{ABSTRACT}

In his Grundrisse, Marx anticipated the transformation of science and technology into direct productive forces in capitalism. This process would make intelectual work superior to manual labor, done by machines. Capital would, then, have to be overrun by some formation based on society's general intellect. Because of that, there is the debate whether the law of value, based on working hours, should be rethought or if it would be necessary to redefine the labor category. This article aims to point out gaps in this debate, linking Marx's concept of historical dialectics with the scientific concepts of information theory. When we relate work to information as negentropy, we understand capital like a ever-expanding bio-social system addicted to knowledge detained by workers. Therefore, we conclude that the capital has evolved to the point of appropriating general intellect. As it evolved, capital reduced the immediate factory working hours, which is subordinate to scientific work, to a minimum. This way, in order to keep accumulating, capital had to develop an income system based on intellectual property and financialization. The law of labor still commands labor relations, but now under new ways of free labor appropriation, precariousness and space-time fragmentation, with over exploration of informational low value work from systemic outskirts.

Keywords: Labor; General intellect; Informational income; Semiotic labor. 


\section{INTRODUCC̆̃O}

O presente texto é fruto de um estudo realizado pelo Grupo Marxiano de Pesquisa em Informação, Comunicação e Cultura (Comarx), que se dedicou, por quase dois anos, à leitura em sua totalidade dos Grundrisse de Karl Marx. O motivo dessa investigação foi a percepção de que a ciência e tecnologia, no capitalismo avançado, se tornaram forças produtivas diretas, sendo necessário fazer um contraponto a leituras recentes que têm chamado a atenção para a expressão general intellect e para a possibilidade de a lei do valor já ter sido superada pela própria evolução do capitalismo. O trabalho humano perderia assim a sua centralidade na produção do valor. $\mathrm{O}$ capitalismo estaria agora se apoiando na apropriação de relações sociais subjetivas, culturais, intangíveis, que muitos autores pretendem resultar de um tipo de trabalho desprovido de materialidade, por isso "imaterial".

É necessário destacar que o conceito de intelecto geral (general intellect) se restringe aos desenvolvimentos feitos por Marx nos Grundrisse, e há uma polêmica sobre a sua utilização. Nós pensamos que, quando se lê os Grundrisse em sua totalidade (não apenas fragmentos), pode-se concluir que, sim, Marx descreveu um sistema social até o seu limite de evolução, mas não que essa evolução pudesse prosseguir num quadro de capitalismo novo ou de novo tipo.

Tal fica claro no seguinte trecho dos Grundrisse:

Na mesma medida em que o tempo de trabalho - o simples quantum de trabalho - é posto pelo capital como único elemento determinante de valor, desaparece o trabalho imediato e sua quantidade como princípio determinante da produção - a criação de valores de uso —, e é reduzido tanto quantitativamente a uma proporção insignificante, quanto qualitativamente como um momento ainda indispensável, mas subalterno frente ao trabalho científico geral, à aplicação tecnológica das ciências naturais, de um lado, bem como [à] força produtiva geral resultante da articulação social na produção total — que aparece como dom natural do trabalho social (embora seja um produto histórico). O capital trabalha, assim, pela sua própria dissolução como forma dominante de produção (MARX, 20I2, p. 589).

Entretanto, essa antevisão não contava com a possibilidade de o capital se apropriar do próprio "intelecto geral"...

Quer dizer, a lógica de Marx não permitiria uma evolução do capitalismo além deste seu atual estágio no qual já vivemos, mas também não nos permite entender esta etapa como um modelo estritamente compatível com a sua lógica original. É verdade, ele pensava que, quando o capital chegasse a esta etapa do general intellect, já não poderia mais ser capital, teria de ser outra coisa, porém aquela sua mesma lógica nos permite abordar o capitalismo de hoje ainda como capitalismo (capital que se autovaloriza e se acumula pelo trabalho), desde que se considere estarmos vivendo em uma nova (e imprevista) etapa. 


\section{O trabalho humano, nesse desenvolvimento} sob o capital, levou o capitalismo a uma nova etapa, que Marx não poderia prever: o próprio intelecto geral apropriado pelo capital. E é o que ocorre hoje, de acordo com nossas conclusões. Então há que se fazer um exercício teórico e político para compreender essa etapa do capitalismo, que não é bem uma "sociedade da informação", mas um capitalismo mais desenvolvido. Os Grundrisse nos permitem entender isso

Para Marx, a evolução do capitalismo levaria a uma etapa em que a ciência e tecnologia viriam a ser forças produtivas plenas, mas ele também afirma que ciência e tecnologia são produto e produção de trabalho, não nascem do nada. Em suas palavras:

A natureza não constrói máquinas, não constrói locomotivas, não constrói telégrafo elétrico, não constrói máquinas filatórias, são produtos da indústria humana. São material natural transformado pelos órgãos da vontade humana sobre a natureza e de sua atividade na natureza. São órgãos do cérebro humano criados pela mão humana; força do saber objetivada. O desenvolvimento do capital fixo indica até que ponto o saber social geral, conhecimento, deveio força produtiva imediata e, em consequência, até que ponto as próprias condições do processo vital da sociedade ficaram sob o controle do intelecto geral e foram reorganizadas em conformidade com ele. Até que ponto as forças produtivas da sociedade são produzidas, não só na forma do saber, mas como órgãos imediatos da práxis social; do processo real da vida (MARX, 20I2, p. 589).

Os produtos da ciência e tecnologia são forças do saber objetivadas. O desenvolvimento do capital fixo indica até que ponto o saber social geral (conhecimento) vem a ser uma força produtiva imediata e, em consequência, até que ponto as próprias condições do processo vital da sociedade tornaram-se barro para o intelecto geral e foram reorganizadas em função dele: como tais, seguiriam sendo sua fonte de valor 
e acumulação. Então é o trabalho humano que constrói tudo isso. Mas o trabalho humano, nesse desenvolvimento sob o capital, levou o capitalismo a uma nova etapa, que Marx não poderia prever: o próprio intelecto geral apropriado pelo capital. E é o que ocorre hoje, de acordo com nossas conclusões. Então há que se fazer um exercício teórico e político para compreender essa etapa do capitalismo, que não é bem uma "sociedade da informação", mas um capitalismo mais desenvolvido. Os Grundrisse nos permitem entender isso.

Portanto, partindo do Marx dos Grundrisse, pretendemos adiante mostrar como ele dialoga com as modernas teorias da informação e comunicação e como essas teorias podem nos ajudar a compreender o capitalismo informacional da nossa época.

\section{A CENTRALIDADE DO TRABALHO}

Afinal, o que Marx disse sobre o trabalho? Qual é o seu conceito de trabalho? Não há muita dúvida sobre isso: o trabalho é uma atividade humana que se diferencia de outras atividades animais por ser comandado pela mente, pelo pensamento. Os seres humanos efetuam alterações em seu ambiente que já haviam projetado em seu cérebro. Isso está escrito n'O Capital. Esse conceito é semiótico: a mente gera, nela, imagens que, em relação prática com o mundo, através do corpo, produzem neste mundo significações conforme são determinadas pelo contexto dessa relação social. O trabalho humano é, antes de mais nada, atividade, movimento. E Marx faz uma distinção clara entre trabalho vivo - trabalho humano - e trabalho morto - trabalho de máquinas. Como ele escreveu n'O Capital:

Uma máquina que não serve no processo de trabalho é inútil. Além disso, sucumbe à força destruidora do metabolismo natural. O ferro enferruja, a madeira apodrece. O fio que não é usado para tecer ou fazer malha é algodão estragado. $\mathrm{O}$ trabalho vivo deve apoderar-se dessas coisas, despertá-las dentre os mortos, transformá-las de valores de uso apenas possíveis em valores de uso reais e efetivos. Lambidas pelo fogo do trabalho, apropriadas por ele como seus corpos, animadas a exercer as funções de sua concepção e vocação, é verdade que serão também consumidas, porém, de um modo orientado a um fim. Como elementos constitutivos de novos valores de uso, de novos produtos. Aptos a incorporar-se ao consumo individual como meio de subsistência ou um novo processo de trabalho como meios de produção (MARX, 20I7, p. 260-26I).

Nessa sentença, Marx nos sugere uma relação clara entre informação e entropia. Os materiais sucumbem às determinações das leis da termodinâmica: tendem a crescente entropia. No entanto, conforme já demonstrado por Brillouin (I988), Atlan (I992) e Prigogine (I992), entre outros, a matéria organizada pode, sob certas condições, produzir transformações não entrópicas ou antientrópicas. Assim, as máquinas, 
na natureza, estão sob ação da entropia. Em contrapartida, o trabalho vivo, o trabalho humano, executa um trabalho neguentrópico, um trabalho cuja finalidade é não permitir que as coisas sejam dissolvidas pela entropia, mas que sejam transformadas e valorizadas para atender às necessidades de sobrevivência da nossa sociedade.

Informação é definida como essa atividade que dissipa energia com a finalidade de recuperar energia, com finalidade neguentrópica (DANTAS, 2012; 2017). A vida é, essencialmente, matéria organizada capaz de realizar esse trabalho informacional. E Marx - que certamente conhecia os estudos de Carnot, Clausius e Maxwell sobre termodinâmica - define claramente o trabalho humano como essa atividade de "dar forma" à matéria "morta", informar a matéria com uma finalidade, a finalidade de sustentar, reproduzir e aperfeiçoar as condições da existência humana. Marx não teria como conhecer o desenvolvimento da teoria da informação que se daria mais tarde, no século XX. Mas essa definição de trabalho que ele nos apresenta deixa claro seu caráter neguentrópico avant la lettre.

Marx comenta:

Que o trabalho é sempre nova fonte da troca para o trabalhador enquanto ele está capacitado para o trabalho - mais precisamente, não da troca pura e simples, mas da troca com o capital - está implícito na própria determinação conceitual de que o trabalhador só vende a disposição temporária sobre sua capacidade de trabalho, que ele sempre pode, portanto, reiniciar a troca tão logo tenha ingerido a quantidade suficiente de matéria para poder reproduzir de novo sua expressão vital (MARX, 20II, p. 228).

O trabalho é sempre um meio de troca para o trabalhador. Logo, ele necessita estar capacitado para o trabalho, porém agora não mais como troca pura e simples (com a natureza, com outros homens e mulheres), mas como troca com o capital. Logo, recuperada a sua neguentropia (capacidade para fornecer trabalho), o trabalhador pode seguir ocupando o seu corpo em fornecer informação para o capitalista, assim valorizando o seu (do capitalista) capital. Se não estivesse nessa relação com o capital, estaria fazendo o quê? Estaria ocupando sua mente e corpo em outras relações sociais: na vida familiar, nas tabernas com amigos e amigas, lendo ou escrevendo um livro, pintando um quadro, admirando a natureza...

Para ingerir uma quantidade suficiente de matéria que lhe reproduza as condições vitais, o ser humano não precisaria trabalhar, nesse sentido produtivo, o dia inteiro. Poucas horas de trabalho lhe seriam suficientes. O capital introduziu relações sociais, ao longo de um processo histórico que durou cerca de três séculos, que praticamente naturalizaram, em todos nós, a ideia de trabalhar produtivamente a maior parte do dia ou da semana, algo que não acontecia até o final do século XVIII e ainda hoje não acontece em muitas sociedades humanas. $O$ dispêndio de trabalho a serviço do capital foi estendido até o limite da disponibilidade entrópica (cansaço máximo) do corpo e mente. Numa parte da jornada diária, o trabalhador troca informação 
(conhecimentos, técnicas, habilidades) pelos bens necessários à reprodução das suas condições vitais (salário). Na outra parte da mesma jornada, ele continua fornecendo ao capital a informação necessária para dar continuidade ao processo produtivo, porém, agora, gratuitamente. Essa é a essência do mais-valor: informação não paga.

Marx, sobretudo nos Grundrisse, muito discute e aprofunda a seguinte questão: quanto mais o capital desenvolve o trabalho excedente, mais tem que desenvolver um consumo excedente, mais tem que criar consumo, produzir consumidores.

[...] A produção de valor excedente relativo, i.e., a produção de valor excedente fundada no aumento e no desenvolvimento de forças produtivas, requer a produção de novo consumo; requer que o círculo de consumo no interior da circulação se amplie tanto quanto antes se ampliou o círculo produtivo. Primeiro, ampliação quantitativa do consumo existente; segundo, criação de novas necessidades pela propagação das existentes em um círculo mais amplo; terceiro, produção de novas necessidades e descoberta e criação de novos valores de uso (MARX, 20II, p. 332-333).

Daí:

Isso não é só divisão do trabalho, essa criação de novos ramos de produção, isto é, de tempo excedente qualitativamente novo; mas a venda de determinada produção dela mesma como trabalho de novo valor de uso; o desenvolvimento de um sistema abrangente em constante expansão de modos de trabalho, modos de produção, aos quais corresponde um sistema de necessidades constantemente ampliado e mais rico (MARX, 20II, p. 333).

Isso faz com que o capital desenvolva nas forças produtivas da sociedade a capacidade e a necessidade de criar novas necessidades de consumo. E tudo isso é capitalismo, não é algo fora do capitalismo. É o capitalismo criando novas necessidades para sua própria necessidade de desenvolvimento. Por isso também desenvolve as forças produtivas do trabalho e a própria qualidade do trabalho. Cria trabalho qualitativamente novo e incorpora à sociedade, cada vez mais, como inerentes à sociedade mesma, essas suas necessidades de expandir quantitativamente e qualitativamente o trabalho de produção de valor.

Essa produção de novas necessidades e de tempo excedente qualitativamente novo veio acontecendo ao longo de todo o século XX. Devemos lembrar que no tempo de Marx não existia luz elétrica, nem todo o sistema de consumo e produção domésticos desenvolvidos a partir da disseminação da eletricidade. Tampouco havia radiodifusão, automóveis etc. Toda uma indústria se desenvolveu a partir daí, ramos de produção e perfis de trabalho totalmente novos. É só no século XX que, nas indústrias e nas empresas em geral, vão se expandir empregos de nível técnico superior: engenharia, economia etc. Muda também a qualidade do trabalho no chão de fábrica, que perde suas características empíricas ou semiartesanais ainda comuns até fins do século XIX. 


\section{A EXPANSÃO DA CONTRADICÃO DO CAPITAL}

Nesse processo, devido à lógica que impulsiona o capital a buscar sempre ampliar o mais-valor, o trabalho vivo produtivo é, ao mesmo tempo, tanto eliminado quanto expandido: reduz-se num segmento produtivo, expande-se em novos segmentos produtivos. Essa é a grande contradição. Marx:

É tendência do capital criar tanto trabalho quanto possível, assim como também é sua tendência reduzir o trabalho necessário ao mínimo. [...] Tanto aumentar a população que trabalha como pôr continuamente uma parte dela como população excedente - população que é inútil, até que o capital possa valorizá-la [...]. É tendência do capital tanto tornar o trabalho humano (relativamente) supérfluo como pressionar simultaneamente o trabalho humano de maneira desmedida (MARX, 20II, p. 323).

Tal tendência implica

[...] Pôr todo o tempo do indivíduo como tempo de trabalho, e daí a degradação do indivíduo a mero trabalhador, sua subsunção ao trabalho. Por isso, a maquinaria mais desenvolvida força o trabalhador a trabalhar agora mais tempo que o fazia o selvagem ou que ele próprio com suas ferramentas mais simples e rudimentares (MARX, 20II, p. 59I).

Quando sabemos que o telefone celular fez de todos nós produtores de valor para o capital na forma dos dados pessoais que fornecemos para Mark Zuckerberg, Jeff Bezos, Sergey Brin etc., ou reduziu milhões de homens e mulheres a trabalhadores precários nessas novas formas, "uberizadas", de relações de trabalho, vemos que essa evolução não seria estranha a Marx. Estranho para ele, talvez, fosse que, a esta altura, a humanidade ainda não tenha encontrado um meio de se livrar do capitalismo...

Talvez a chave para explicar essa contradição, de um ponto de vista marxiano, esteja na seguinte passagem:

Os trabalhos efetivamente livres, p. ex., compor, são justamente trabalhos ao mesmo tempo da maior seriedade e do mais intenso esforço. O trabalho da produção material só pode adquirir tal caráter: I) se seu caráter social é posto; 2) se é simultaneamente trabalho de caráter científico e geral, e não esforço do ser humano como força natural adestrada de maneira determinada, mas como sujeito que aparece no processo de produção não só em forma simplesmente natural, emergindo diretamente da natureza (naturwüchsig), mas como atividade que regula todas as forças da natureza (MARX, 20II, p. 509).

Ou seja, uma sociedade pós-capitalista, uma sociedade na qual o conjunto dos seres humanos poderia realizar trabalhos efetivamente livres, seria aquela que permitisse ao conjunto dos seres humanos se dedicar a atividades de natureza artística ou 
científica. Uma sociedade assim é possível? Talvez sim, quando percebemos a imensa quantidade de jovens que busca sobreviver, hoje em dia, em atividades artísticas ou desportivas. Por outro lado, como nem todo mundo dispõe do necessário talento, mas, sobretudo, porque o capitalismo também precisa condicionar essas atividades às suas necessidades de acumulação, sem falar nos limites de poder ou controle político que precisa impor à liberdade artística ou cultural, o capital não pode expandir, em todo o seu potencial, essa capacidade humana de gerar aquilo que Marx denominava "efetiva riqueza". A riqueza, para Marx, não seria o mero acúmulo de bens materiais ou de dinheiro, mas, sobretudo, esse desenvolvimento da livre capacidade criativa da mente social humana. Para esse desenvolvimento seria necessário tempo livre, ou disposable time, como escreve nos Grundrisse: um tempo de não trabalho (considerando-se trabalho no sentido de atividades que satisfazem às necessidades vitais do corpo), mas de plena produção criativa no atendimento às demandas sociais da mente humana:

O tempo livre, que é tanto tempo de ócio quanto tempo para atividades mais elevadas, naturalmente transformou o seu possuidor em outro sujeito, e é inclusive como este outro sujeito que ele então ingressa no processo de produção imediato. Esse processo é disciplina, no que se refere ao ser humano em formação, e ao mesmo tempo experiência prática, ciência experimental e ciência materialmente criativa e que se objetiva, no que se refere ao ser humano já formado, em cujo cérebro existe o saber acumulado da sociedade (MARX, 20II, p. 594).

Sugerimos que essa enorme economia do espetáculo, da cultura, do consumo e do lazer, que hoje comanda efetivamente o capitalismo, está ocupando milhões de homens e mulheres exatamente nesse "tempo livre", nesse tempo de "ócio", como o entendia Marx. Porém não naquelas condições livres, não alienadas, com as quais Marx talvez sonhasse. Justamente ao contrário, o trabalho "artístico" e o "científico" também caíram sob o comando do capital, também foram postos a serviço da sua acumulação e expansão. Tratar-se-ia de um "outro sujeito" que não se identifica a si mesmo como "trabalhador", mas, de fato, ainda é um trabalhador vendendo sua força de trabalho para o capital. Em troca de remunerar suas necessidades de recomposição das demandas do corpo, que, nas condições contemporâneas, incluem uma ampla gama de satisfações subjetivas de consumo, o capital dele extrai trabalho concreto, valor de uso, na forma de suas amplas potencialidades criativas enquanto cientista, artista, desportista etc.

\section{0 CAPITAL E O EQUUILÍBRIO}

Marx, ao analisar o capitalismo no século XIX, o descreve como um sistema que pode ser entendido como cada vez mais longe do equilíbrio, no sentido termodinâmico dessa expressão. Tal desenvolvimento é digno de nota, pois a ciência de sua época era uma ciência do equilíbrio; mesmo a física termodinâmica, a física de 


\section{O fetichismo da mercadoria é essa relação} semiótica que transfere para as "coisas" o poder de intermediar as relações sociais humanas, de constituir o canal de comunicação dos seres humanos na sociedade capitalista. Assim, a tendência não apenas econômica, mas também inerentemente cultural, seria, cada vez mais, fazer do signo ele mesmo, não importa seu substrato material, o próprio objeto da transação mercantil. Observe-se que nada há de "imaterial" aí: o signo é necessariamente material, é algum substrato energético-material que a sociedade, culturalmente, estabelece como ferramenta de comunicação

Maxwell, era uma física do equilíbrio. E Marx a mostra, quando descreve a circulação simples como uma circulação de equilíbrio e depois avança para a circulação ampliada como uma circulação tipicamente capitalista: aqui ele está descrevendo um sistema que tendia cada vez mais para longe do equilíbrio.

Essa percepção sobre o sistema leva à possível conclusão lógica de que, a longo prazo, o capitalismo seria um sistema que não teria viabilidade, porque iria produzir um crescente desequilíbrio no consumo dos recursos naturais e na própria vida em sociedade. A teoria do valor é uma teoria do não equilíbrio que explica por que o capital pôs a humanidade para produzir além do essencial para a sua reprodução. Para Marx, porém, tratava-se de uma ruptura histórica necessária para levar a humanidade a um novo patamar civilizatório no qual aquela parte da sociedade que era posta para trabalhar - enquanto outra podia viver no "ócio" - também seria liberada do trabalho pelo avanço dos sistemas automáticos de maquinaria. Marx acreditava que nessa nova fase, dominada por um general intellect libertado do poder capitalista, a humanidade se organizaria conforme uma presumível sociedade comunista.

Não foi o que aconteceu. Ao menos até agora. Porém, sua teoria do valor, associada a elementos da teoria da informação e da termodinâmica, nos oferece instrumentos para o estudo e compreensão da lógica atual de uma sociedade que segue longe do equilíbrio. 


\section{APROPRIAÇÃO DO GENERAL INTELLECT}

O que esses trabalhadores não trabalhadores produzem?

Produzem signos: imagens, marcas, espetáculos, pois para Marx (20II, p. 9I) “a mercadoria é simples signo, uma letra para uma relação de produção, um simples signo para seu próprio valor". Essas imagens e marcas são o cerne da "sociedade do espetáculo", termo cunhado por Debord (1997).

Seguindo essa trilha, afirmamos que a teoria marxiana do valor é essencialmente semiótica (EAGLETON, I993; WILDEN, 200I; DANTAS, 20I8): a mercadoria é um signo cujo símbolo mais evidente é o dinheiro. Em termos peirceanos, o valor de uso é o fundamento ou objeto do signo mercantil. O valor de troca seria o representamen, ou signo ele mesmo. E o valor, cuja substância é o trabalho humano, seria o próprio interpretante dessa relação mercantil, o sujeito social que sintetiza essa relação na produção para troca e consumo destinados a valorizar capital (DANTAS, 20I8). O fetichismo da mercadoria é essa relação semiótica que transfere para as "coisas" o poder de intermediar as relações sociais humanas, de constituir o canal de comunicação dos seres humanos na sociedade capitalista. Assim, a tendência não apenas econômica, mas também inerentemente cultural, seria, cada vez mais, fazer do signo ele mesmo, não importa seu substrato material, o próprio objeto da transação mercantil. Observe-se que nada há de "imaterial” aí: o signo é necessariamente material, é algum substrato energético-material que a sociedade, culturalmente, estabelece como ferramenta de comunicação. Que a produção e o consumo da mercadoria tenham evoluído para se tornar produção e consumo da marca da mercadoria, isso estaria plenamente conforme à lógica evolutiva do capital, ao seu processo de permanentemente criar novas necessidades e, logo, também novos perfis de trabalho para a produção e para o consumo dessas novas necessidades.

A questão que se vai colocar aqui é a da apropriação.

A mercadoria, nos termos de Marx, é trabalho objetivado, trabalho congelado, trabalho morto. É um objeto cujo valor de uso deve ser alienado, deve trocar de proprietário a fim de realizar o seu valor. No entanto, estamos falando de uma economia cujo objeto da negociação mercantil não é alienável: você "consome" uma música, um filme ou um jogo de futebol, mas não se torna proprietário exclusivo desses valores. São "bens não rivais", na linguagem da economia neoclássica, ou, numa linguagem também liberal, porém mais atual, são “bens comuns”. Há uma contradição intrínseca entre a natureza social do trabalho que produz esses valores de uso e sua apropriação privada pelo capital. Aqui, de fato, a teoria de Marx não nos fornece uma resposta direta: o general intellect deveria corresponder a um novo tipo de organização social pós-capitalista. Mas o capitalismo deu uma resposta para esse problema, resposta pouco estudada pelos marxistas: os direitos de propriedade intelectual. A produção do trabalho científico ou do trabalho artístico é apropriada pelo capital na forma de patentes, copyrights, direitos de imagem etc. Desse modo, sobre esse fundamento, evoluiu todo um sistema de apropriação rentista do trabalho humano que, hoje, está na 
base do desenvolvimento do capitalismo informacional contemporâneo em estreita articulação com o capital financeiro.

Em outras palavras, o capital evoluiu de modo a tornar o general intellect, forma avançada do trabalho social geral da humanidade (ou de parte dela), sua principal fonte de valorização. O capital se apropriou do general intellect. E nada demonstra isso de modo mais contundente do que a valorização que o capital financeiro extrai das plataformas sociodigitais da internet, do trabalho não pago de bilhões de pessoas que fornecem seus dados para "monetização". Essas pessoas expõem nessas plataformas os seus desejos, afetos, necessidades, opiniões, crenças, ou seja, a produção de suas mentes sociais ou intelectos sociais, produção essa que os algoritmos das plataformas reduzem a dados monetizáveis, dos quais podem obter lucros extraordinários (SCHOLZ, 20I3; DANTAS, 20I9).

\section{CONSIDERACִÕES FINAIS}

Discutimos vários trechos dos Grundrisse tentando demonstrar que o capital chega a um ponto em que, para a sua autovalorização e acumulação, se baseia principalmente no trabalho científico, no trabalho artístico, no trabalho realizado em espetáculos, nos esportes e nas redes digitais (DANTAS, 20II). Nessas atividades encontra-se o núcleo do processo de autovalorização do capital. Nem sempre elas são pensadas como trabalho no sentido do inglês labour, no entanto tornaram-se, no capitalismo avançado, também atividades que produzem valor, ou reduziram-se a labour conforme a ressignificação dada por Marx a esta palavra ${ }^{1}$. Porque produz valor para o capital, esse trabalho de natureza basicamente semiótica passou a ser também trabalho produtivo, no exato conceito marxiano de "produtivo" - produtivo para o capital.

A ideia de que, a rigor, o capital se apropria do conhecimento contido e expresso no trabalho vivo, trabalho concreto, estava presente não somente nos Grundrisse, mas também, antes deles, já vinha sendo elaborada por Marx desde, pelo menos, os Manuscritos econômico-filosóficos. O capitalismo sempre foi "cognitivo", isto é, sempre empregou o trabalhador para se apropriar do conhecimento contido e manifestado pelo trabalho. A questão é que hoje em dia o capital reorganizou o processo produtivo para se apropriar do mais-valor produzido no trabalho determinantemente criativo (científico, artístico etc.), e todo o trabalho a que chamamos redundante (repetitivo) tende a ser reduzido às operações dos sistemas automáticos de maquinaria que, nas

1 Cabe lembrar que, no tempo de Marx, as atividades intelectuais, fossem científicas, fossem artísticas, fossem mesmo profissionais liberais, raramente estavam inseridas em relações capitalistas. Eram, na grande maioria dos casos, "serviços" individuais pagos pelo "cliente" direto (aulas particulares, por exemplo), e, em outros casos, atividades sustentadas pelo Estado ou por mecenas, quando não efetuadas por aristocratas que podiam viver das suas rendas. Embora, num ou noutro momento, Marx fizesse referência a elas, sobretudo para exemplificar a diferença entre trabalho produtivo (aquele definido como trabalho que valoriza capital) e improdutivo, seu foco está todo voltado para o trabalho industrial-fabril. Somente a partir das primeiras décadas do século XX, o capital, expandindo os circuitos de trabalho, passaria cada vez mais a incorporar aos processos de valorização, logo, ao conceito de trabalho produtivo, também o trabalho científico, artístico e outros que têm por objeto a produção imediata de material semiótico (projetos, estudos, cursos, imagens etc.). 
últimas décadas, vieram, cada vez mais, incorporando também algoritmos de processamento e comunicação de dados extraídos do trabalho, pago ou não pago, de toda a sociedade. Uma nova "revolução", denominada "4.0", ameaça liquidar as últimas frentes de trabalho redundante como as ainda ocupadas na indústria têxtil. Cresce uma população excedente "global", sem valor de uso para a acumulação. O capital não sabe o que fazer com ela. Talvez isso explique o que já vem sendo chamado "necropolítica", o extermínio da população "sobrante"...

Essa é uma evolução que pode ser deduzida dos Grundrisse, embora escritos no século XIX. Para compreender este capitalismo em que vivemos, não cabem exercícios teóricos ou discursivos para contornar a lei do valor, pelo contrário: é necessário desenvolver a análise do capitalismo até o seu limite, como Marx nos ensinou nos Grundrisse. Nós estamos vivendo esse limite, mas sob o capital que segue comandando trabalho material, pois o trabalho de produzir "gostos", "desejos", "afetos", conforme expresso nas marcas e comportamentos de consumo, é ainda um trabalho de corpo e de produção de signos materiais. Se o resultado desse trabalho não pode ser apropriado pela troca mercantil, é apropriado, como renda, pelos direitos de propriedade intelectual.

O capitalismo sempre foi "cognitivo", isto

é, sempre empregou o trabalhador para se apropriar do conhecimento contido e manifestado pelo trabalho. A questão é que hoje em dia o capital reorganizou o processo produtivo para se apropriar do mais-valor produzido no trabalho determinantemente criativo (científico, artístico etc.), e todo o trabalho a que chamamos redundante (repetitivo) tende a ser reduzido às operações dos sistemas automáticos de maquinaria que, nas últimas décadas, vieram, cada vez mais, incorporando também algoritmos de processamento e comunicação de dados extraídos do trabalho, pago ou não pago, de toda a sociedade 
A propriedade intelectual das diferentes formas de conhecimento (científico-tecnológicas, artísticas, desportivas, lúdicas etc.) tornou-se o objeto central do processo de acumulação e apropriação. Produto do trabalho social geral (ou general intellect), realiza-se como renda em um novo regime de acumulação comandado pelo capital financeiro (DANTAS, 20II; 20I4; 20I7; ORMAY, 20I8; PAULANI, 2OI6; RIGI, 2OI4).

* Professor titular da Escola de Comunicação da Universidade Federal do Rio de Janeiro (UFRJ), doutor em Engenharia da Produção (Coppe-UFRJ), professor e pesquisador dos Programas de Pós-Graduação em Comunicação e Cultura (PPGCOM/ECO) e em Ciência da Informação (PPGCl/lbict-ECO) da UFRJ. Membro do Comitê Gestor da Internet no Brasil (CGI.BR) e do Conselho de Administração do Núcleo de Informação e Coordenação do Ponto BR (NIC.BR). Diretor-executivo do Centro Internacional Celso Furtado para Estudos do Desenvolvimento, sócio da Ulepicc, da Ancib e da Intercom. Integrante do grupo de pesquisa Política e Economia da Informação e Comunicação (Peic) e líder do Grupo Marxiano de Pesquisa em Informação, Comunicação e Cultura (Comarx). Autor de A lógica do capital-informação (Contraponto, 2002) e Trabalho com informação (CFCH-UFRJ, 2012).

** Doutoranda em Comunicação e Cultura pela UFRJ, e mestra em Comunicação e Semiótica pela Pontifícia Universidade Católica de São Paulo (PUC-SP). Bacharela em Comunicação Social, com habilitação em Jornalismo, e especialista em Democracia Participativa, República e Movimentos Sociais pela Universidade Federal de Minas Gerais (UFMG). Jornalista e ativista pela democratização da mídia, filiada à Sociedade Brasileira para o Progresso da Ciência (SPBC), estuda o estabelecimento de cotas de programação nacional na TV por assinatura no Brasil. Integrante do Peic e do Comarx.

E-mail: luanabonone@gmail.com

*** Doutoranda e mestra em Ciência da Informação pelo Instituto Brasileiro de Informação em Ciência e Tecnologia (lbict), em parceria com a UFRJ. Bacharela em Comunicação Social, produtora audiovisual e ativista pela democratização da mídia, estuda as lacunas no regime de informação brasileiro sobre população e território. Integrante dos grupos de pesquisa Peic, Perspectivas Filosóficas em Informação (Perfil-i) e Comarx.

E-mail: niquefig@gmail.com

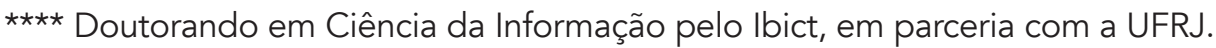

Bacharel e licenciado em Ciências Sociais, e mestre em Políticas Públicas, Estratégias e Desenvolvimento (PPED) no Instituto de Economia, pela UFRJ. Tem experiência na área de sociologia do conhecimento, estuda a economia política das plataformas. Integrante do Peic e do Comarx.

E-mail: rodduarte@yahoo.com.br 


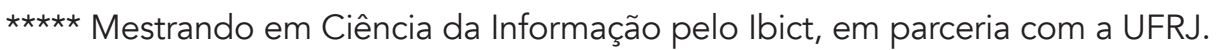
Bacharel em Comunicação Social, com habilitação em Produção Editorial, pelo Centro Universitário de Belo Horizonte (UNIBH). Integra o Comarx.

E-mail: tiago@tiagotadeu.com

Artigo publicado originalmente em Nuestra Bandera, revista do Partido Comunista da Espanha, $n^{\circ} 246,1^{\circ}$ trimestre de 2020 . Traduzido do castelhano original e ligeiramente adaptado para a revista Princípios pelos autores.

Texto recebido em maio de 2020; aprovado em junho de 2020.

ATLAN, Henri. Entre o cristal e a fumaça. Rio de Janeiro: Jorge Zahar, 1992.

BRILLOUIN, Léon. La science et la théorie de l'information. Paris: Éditions Jacques Gabay, 1988.

DANTAS, Marcos. As rendas informacionais e a apropriação capitalista do trabalho científico e artístico. In: MARQUES, Rodrigo Moreno et al. (Org.). A informação e o conhecimento sob as lentes do marxismo, Rio de Janeiro: Garamond, 2014.

. Information as work and as value. Triple C, Rio de Janeiro, v. 15, n. 2, p. 816847, 2017. Disponível em: <http://marcosdantas.com.br/conteudos/05/18/information-as-work-and-as-value>. Acesso em: 30 maio 2020.

. Milionários nada por acaso: capital rentista e apropriação do trabalho artístico nas redes do espetáculo. Eptic On-line, Aracaju, v. XIII, n. 2, maio/ago. 2011. Disponível em: <http://marcosdantas.com.br/conteudos/wp-content/uploads/2013/04/Milionarios-nada-por-acaso.pdf>. Acesso em: 30 maio 2020.

. Semiótica da mercadoria: para uma introdução à economia política do signo. Revista Eptic, Aracaju, v. 20, n. 1, p. 139-160, jan./abr. 2018. Disponível em: <http:// marcosdantas.com.br/conteudos/2018/11/07/semiotica-da-mercadoria-para-uma-introducao-a-economia-politica-do-signo>. Acesso em: 30 maio 2020.

. The financial logic of internet platforms: the turnover time of money at the limit of zero. Triple C, Rio de Janeiro, v. 17, n. 1, p. 132-158, 2019.

. Trabalho com informação: valor, acumulação, apropriação nas redes do capital. Rio de Janeiro: CFCH-UFRJ, 2012. Disponível em: <http://marcosdantas.com.br/ conteudos/2016/03/04/trabalho-com-informacao-valor-acumulacao-apropriacao-nas-redes-do-capital>. Acesso em: 30 nov. 2020. 
DEBORD, Guy. A sociedade do espetáculo. Rio de Janeiro: Contraponto, 1997.

EAGLETON, Terry. A ideologia da estética. Rio de Janeiro: Zahar, 1993.

MARX, K.. O Capital: crítica da econômica política. Livro 1: o processo de produção do capital. São Paulo: Boitempo, 2017.

Grundrisse: manuscritos econômicos de 1857-1858. São Paulo: Boitempo, 2011.

Manuscritos econômico-filosóficos. São Paulo: Boitempo, 2008.

ORMAY, Larissa. Propriedade intelectual e renda no capital-informação. 2018. Tese (Doutorado em Ciência da Informação) — Instituto Brasileiro de Informação em Ciência e Tecnologia; Escola de Comunicação da Universidade Federal do Rio de Janeiro, Rio de Janeiro, 2018.

PAULANI, Leda Maria. Acumulação e rentismo: resgatando a teoria da renda de Marx para pensar o capitalismo contemporâneo. Revista de Economia Política, São Paulo, v. 36, n. 3, p. 514-535, jul./set. 2016.

PRIGOGINE, Ilya; STENGERS, Isabelle. Entre o tempo e a eternidade. São Paulo: Companhia das Letras, 1992.

RIGI, Jakob. Foundations of a Marxist theory of the political economy of information: trade secrets and intellectual property, and the production of relative surplus value and the extraction of rent-tribute, Triple C, Rio de Janeiro, v. 12, n. 2, p. 909-936, 2014.

SCHOLZ, Trebor (Ed.). Digital labor: the internet as playground and factory. Nova York: Routledge, 2013.

WILDEN, Anthony. Informação. In: Enciclopédia Einaudi, v. 34, p. 11-77. Lisboa: Imprensa Nacional, 2001. 